\title{
DESIGN, OPERATION AND ECONOMIC ANALYSIS OF AUTONOMOUS HYBRID PV-DIESEL POWER SYSTEMS INCLUDING BATTERY STORAGE
}

\author{
Demetrios P. Papadopoulos * Eleftherios Z. Maltas *
}

\begin{abstract}
This paper presents a systematic techno-economic analysis of autonomous PV-Diesel energy system with battery storage. This hybrid type power system was developed and installed on the roof of the Electrical Engineering Laboratory building in the city of Xanthi, Greece, where a weather station is also installed providing necessary meteorological data since 2002. Such system can be generally used to supply electrical loads of isolated remote areas. The actual design of such a system is based on: a pre-defined load pattern to be supplied; the pertinent weather data; the relevant market prices; and the applicable recent economic rates (eg June 2009 for the Greek case). The system is operated on a predictive manner using a Programmable Logic Controller (PLC) which controls the main system parameters for safe and continuous power supply to meet reliably the desired load demand. Three distinct systems of this type and of equal capacity, which combine energy sources and battery storage have been proposed and assessed technically and economically.
\end{abstract}

K e y w ords: diesel generator, PV generator, battery bank, bidirectional inverter, programmable logic controller

\section{INTRODUCTION}

Electrification of isolated or remote areas has been a subject of consideration ever since electricity started to affect human activities. In these areas the geographic adverse conditions and/or the increased cost to expand the utility grid usually lead to the implementation of autonomous power energy systems[1-3]. In previous decades the relatively low cost of operation and maintenance (O\&M) of a diesel generator (DG) based mainly on the low prices of fuel, along with the high initial cost for PV generators (PVGs) and the required power electronics, resulted in extended use of DGs to supply power to meet load demand in remote areas [4-7]. The conducted steady and systematic Research and Development (R\&D) of PVs and their related Balance Of System (BOS) have caused a significant decline in the associated prices. On the other hand, the constant increases in energy demand and the related utilization of natural resources have caused enormous increase in fuel prices. These factors have made the renewable energy sources (RES) a viable supplement and perhaps a main alternative to be used in remote areas where the cost of O\&M and the fuel cost of DGs are relatively high [8].

The advantages wrt. implementing PVs in an autonomous system are several [9], but there is a real disadvantage concerning limited system reliability when there is no solar irradiation for a longer period than the one being considered by the designer for storage capacity of the system. In such a case, the energy stored in the battery bank due to economic reasons cannot meet fully the load requirements [10]. On the contrary, the non constant yearly energy production of the PVG may lead to over design and thus to a more expensive PVG with relatively greater battery storage capacity in order to meet the load requirements. The unnecessarily larger size of PVGs and ratings of the needed inverter can be avoided by using a combination of a conventional energy source to supply power, especially when the peak load demand is much higher than the capacity of the PVG. In such cases the use of a DG to supply the required load power, while it simultaneously charges the battery, results in providing the necessary reliability and cost effectiveness characterizing the overall hybrid power system (HPS) [11].

This paper presents three competing power systems, with equal capacity, serving the same load, which were proposed, developed and tested for their reliability, efficiency and cost effectiveness. These three investigated systems were: 1) a DG one, 2) a DG-battery one, and 3) a PV with DG-battery one. The operating requirements and associated costs of the examined three power systems (PSs) were used to perform the desired economic analysis.

A weather station was used to provide the necessary meteorological data, which in turn were processed accordingly for the purpose of estimating the energy the PVG may yearly produce. A pre-defined variable daily load pattern demand was selected and supplied separately by the examined three different PSs. A different control strategy was proposed and followed for each PS using a PLC, which was properly programmed for each of the three cases.

Laboratory of Electrical Machines Dept. of Electrical and Computer Engineering, Democritos University of Thrace, Vasilissis Sofias 12, 67100, Xanthi, Greece, dpapadop@ee.duth.gr 


\section{OVERVIEW OF AUTONOMOUS PS OPERATION}

\subsection{Meteorological data acquisition and process- ing}

The meteorological data wrt a site are usually obtained through actual measurements or by using correlationprediction methods with reference to another site. As PV designers aim to secure maximum economic return of the required investment, usually global irradiation, ambient temperature, wind speed at the actual site should be extracted and properly assessed for a period of time (preferably for more than one year).

Typical and mostly used integration of global irradiation is the monthly daily mean irradiation, $\left(G_{d}\right)_{m}$, given by [12]

$$
\left(G_{d}\right)_{m}=\frac{1}{\left(m_{2}-m_{1}\right)} \sum_{N=m_{1}}^{m_{2}} G_{d}
$$

where $G_{d}$ in $\mathrm{W} / \mathrm{m}^{2}$ is the daily global irradiation, $m_{1}$ is the first day of the examined month, and $m_{2}$ is the last day of the examined month.

Cell temperature $T_{c}$ in ${ }^{\circ} \mathrm{C}$ is another parameter which alters the performance of a PVG. An increase of $T_{c}$ causes associated increase of the PVG's current, but also associated noticeable decrease in PVG's voltage and power. If the meteorological station provides only the ambient temperature and the global solar irradiation, then the cell temperature can be approximated by [13]

$$
T_{c}=T_{a}+0.02 G
$$

where, $T_{a}$ is the ambient temperature.

Furthermore, if the wind speed $u$ in $\mathrm{m} / \mathrm{s}$ is given at the actual site, then $T_{c}$ can be better approximated by [14]:

$$
T_{c}=3.12+0.899 T_{a}+0.025 G-1.3 u .
$$

If $G$ and $T_{c}$ are known, then [15-16]:

$$
P\left(G, T_{c}\right)=P_{S T C} \frac{I_{S C}\left(G, T_{c}\right) V_{o c}\left(G, T_{c}\right)}{I_{S C_{S T C}} V_{o c_{S T C}}}
$$

where $P\left(G, T_{c}\right), I_{S C}\left(G, T_{c}\right)$ and $V_{o c}\left(G, T_{c}\right)$ are the power, the short-circuit current and the open-circuit voltage of the PV module at $\left(G, T_{c}\right)$ conditions, respectively; and $P_{S T C}, I_{S C_{S T C}}$ and $V_{O c_{S T C}}$ are the power, the shortcircuit current and the open-circuit voltage of the $\mathrm{PV}$ module at STC, respectively and are given by the manufacturer of the PV module.

\subsection{Energy production by the PVG}

The energy being produced by the PVG is proportional to the global irradiation. It is also related to the temperature of the cell and the air mass. For the PVG sizing the following systematic procedure can be used [17]
The daily required energy, $E_{P V}^{\prime}$, in Ah from the PVG is

$$
E_{P V}^{\prime}=\frac{E_{P V}}{V_{s}}
$$

where: $E_{P V}$ is the required energy in Wh and $V_{s}$ is the system voltage on the $\mathrm{DC}$ side in $\mathrm{V}$.

Taking into consideration the inverter losses and the meteorological data the required design current $I_{d}$ in $\mathrm{A}$ of the PVG is

$$
I_{d}=\frac{E_{P V}^{\prime}}{t_{p s h} n_{i n v} f_{p v}}
$$

where, $t_{p s h}$ are the peak-sun hours of the considered month for the design in hrs, and $f_{p v}$ is the derating factor of the PVG. Then the number of modules $m_{p}$ connected in parallel is

$$
m_{p}=\frac{I_{d}}{I_{m}}
$$

where: $I_{m}$ in A is the PV module current in STC. Similarly, the number of modules $m_{s}$ connected in series is

$$
m_{s}=\frac{V_{s}}{V_{m}}
$$

where $V_{m}$ is the module voltage in $\mathrm{V}$.

\subsection{Energy production by the DG}

The power which may be supplied to an autonomous system by the DG is equal to the total load demand. If not given by the manufacturer of the $\mathrm{DG}$, the fuel consumption (FC) vs the supplied load (SL) curve should be established as follows

$$
F C=a \times S L+b
$$

where only two points are needed. These two measurements are usually taken for $40 \%$ and $80 \%$ operation of the DG wrt nominal output power.

The coefficients $a$ and $b$ can be calculated using the least square method for a number of experimental measurements as follows

$$
a=\frac{N \sum\left(S L_{i} \times F C_{i}\right)-\sum S L_{i} \sum F C_{i}}{N \sum S L_{i}^{2}-\left(\sum S L_{i}\right)^{2}}
$$

and

$$
b=\frac{\sum F C_{i}-a \sum S L_{i}}{N}
$$

where, $i$ is the examined measurement $(i e 1,2, \ldots, N)$, $S L_{i}$ is the load being supplied and $F C_{i}$ is the fuel being consumed by the DG when it supplies load $S L_{i}$. The above mentioned curve is of significant importance for the economic assessment of every PS for possible use. Similarly, the efficiency $n_{D G}$ of the DG is strongly dependent on the load it supplies and is given by

$$
n_{D G}=\frac{P_{o u t}}{P_{\text {in }}}=\frac{S L}{M C V \times F C}
$$




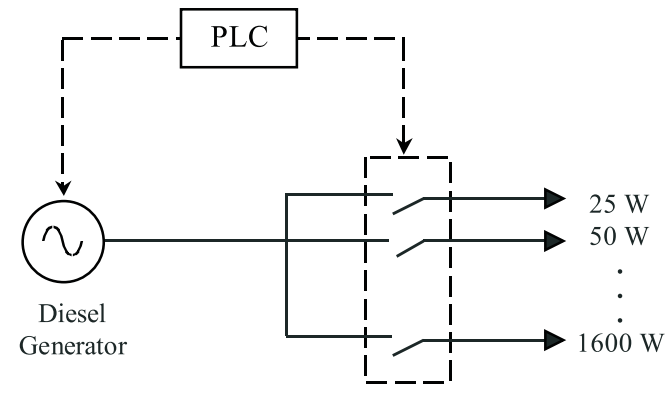

(a)

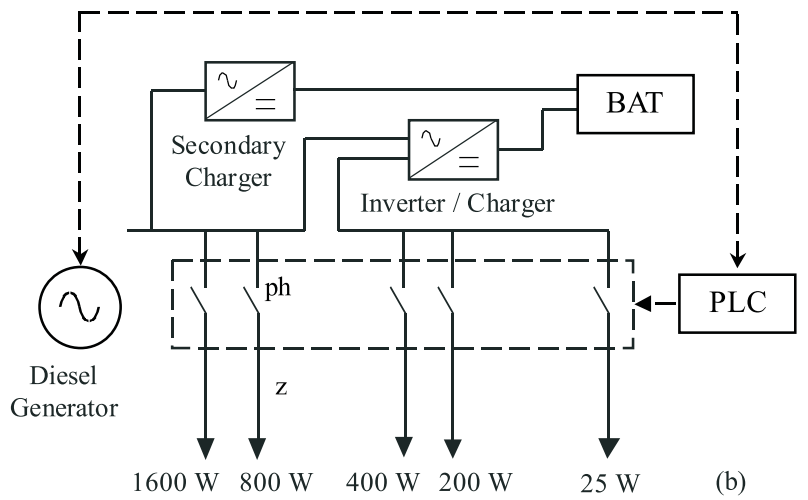

$1600 \mathrm{~W} \quad 800 \mathrm{~W} \quad 400 \mathrm{~W} 200 \mathrm{~W} \quad 25 \mathrm{~W}$ (b)

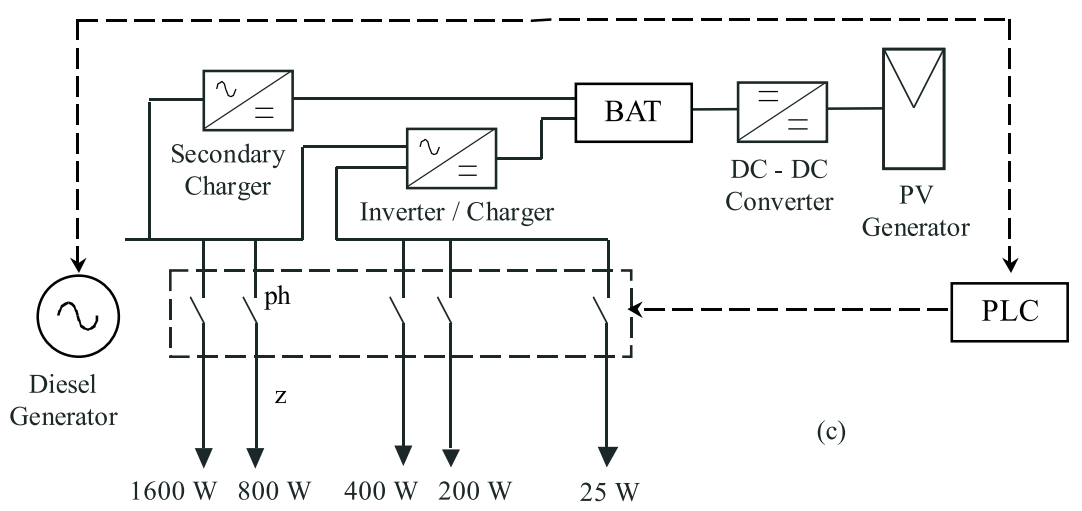

Fig. 1. The three distinct topologies of the examined PSs: (a) PS1 configuration, (b) PS2 configuration, (c) PS3 configuration

where $M C V$ is the Minimum Calorific Value (considered $9.58 \mathrm{kWh} / \mathrm{lt})[18]$.

By using (9), then (12) may be transformed to

$$
n_{D G}=\frac{P_{\text {out }}}{P_{\text {in }}}=\frac{S L}{M C V(a \times S L+b)} .
$$

If the load to be supplied is less than $30 \%$ of the DG rating capacity, the DG operation should be prevented not only due to its low performance, but mainly due to the damage the machine may suffer, which will limit its useful life [19]. In such a case, either the load should be supplied by the battery or the charger itself should have enough rated power to charge the battery (without causing damage to it) and the total load being served should be rated close to $7089 \%$ of the DG nominal power output [19].

\subsection{Battery bank}

The battery bank combined with the inverter's output power should support as much of the load demand as possible in order to avoid frequent (unnecessary) use of the DG. When designing a hybrid PV-DG system the selection of the battery is a significant factor, since its capacity determines not only the energy it can supply but also the peak load that can be served by the battery-inverter subsystem (due to the voltage drop of the battery, which is a function of the supplied load and at the same time is the input voltage of the inverter). In general the capacity of battery is calculated as follows [17]

$$
E_{B A T}=\frac{E_{L-B A T} d}{n_{i n v} V_{s} n_{c} n_{t} D O D n_{b a t}}
$$

where, $E_{B A T}$ is the required battery capacity in $\mathrm{Ah}$, $E_{L-B A T}$ is the daily supplied energy to the load by the battery in $\mathrm{Ah} / \mathrm{d}, d$ is the number of days the battery can supply the load, $n_{i n v}$ is the efficiency of the inverter, $V_{s}$ is the system voltage on the DC side in $\mathrm{V}, n_{c}$ is the cable efficiency, $n_{t}$ is the temperature efficiency, $D O D$ is the used depth of discharge, and $n_{b a t}$ is the efficiency of the battery.

\subsection{Bidirectional Inverter (Inverter-Charger)}

The inverter nominal output power specifies the peak load that can be supplied. In a hybrid PV-DG power system an inverter with nominal power output less than the peak load demand can be used when the peak load is directly supplied by the DG. In most cases, when the base load and the peak load of the PS do not have significant fluctuations, it is preferable to implement an inverter that can supply the peak load, which results in a PS fully controlled by the inverter, and thus decreasing significantly the other related time intervals (eg DG startup period etc) where no load can be served. When the DG is in operation the bidirectional inverter becomes a charger of the battery and all the load is supplied by the DG. 


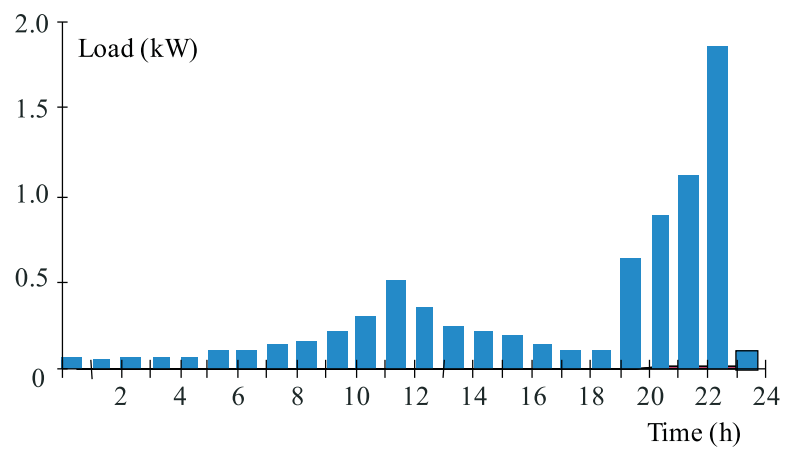

Fig. 2. PLC controlled daily load pattern demand

Table 1. Composition components of the examined three PSs

\begin{tabular}{lccc}
\hline & \multicolumn{3}{c}{ Examined Power Systems } \\
& PS1 & PS2 & PS3 \\
\hline DG(One unit & + & + & + \\
Yanmar YDG 3000SE) & & & \\
PV (6 units Eurosolare & - & - & + \\
PL-810) & & & \\
Bidirectional Inverter & - & + & + \\
$\begin{array}{l}\text { (1 unit APSX 1250) } \\
\text { Secondary Charger }\end{array}$ & & & \\
$(1$ unit Micro 1260 Emmis) & - & + & + \\
Battery Bank (10 units & - & & \\
Winner Apollo 100 Ah-12V) & & + & + \\
\hline
\end{tabular}

\subsection{Economic Analysis}

In modern competitive energy markets it is essential that every PS must prove also, besides its technical feasibility, its economic viability. The generally accepted economic criteria used for such evaluation are the following [20-22]

- Net Present Cost (NPC).

- Net Present Value (NPV).

- Internal Rate of Return (IRR).

- Pay Back Period (PBP).

- Benefit to Cost Ratio (BCR).

- Cost Of Energy (COE).

From the above criteria the COE refers to each PS individually, whereas the other indices refer to comparisons between two PSs, one of which is considered to be the reference PS.

\section{CASE STUDY}

\subsection{Experimental system configuration}

For evaluation purposes a PS (in the form of Fig. 1) being installed on the roof of the Electrical Engineering Laboratory building in the city of Xanthi, Greece was examined. The three different PS topologies, serving the

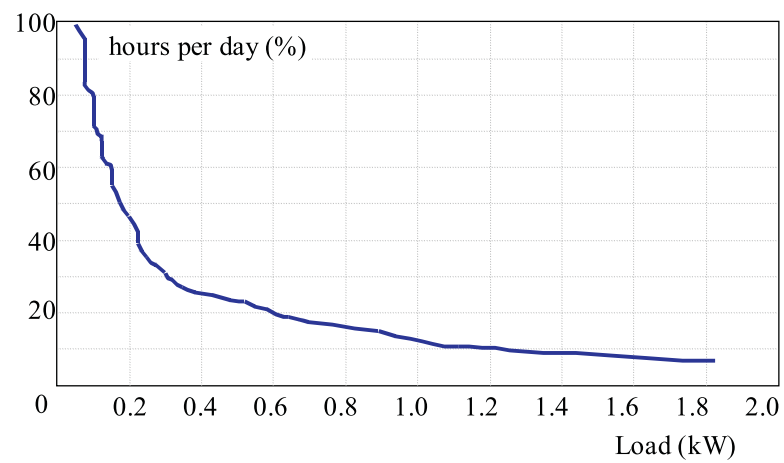

Fig. 3. Daily load duration curve

same load, are composed as shown in Table 1 and are investigated thoroughly.

Various discrete loads: $25 \mathrm{~W}, 50 \mathrm{~W}, 100 \mathrm{~W}, 800 \mathrm{~W}$, and $1600 \mathrm{~W}$ are used to develop any desirable load pattern demand. The above mentioned loads can be switched on and off using suitable PLC commands. The size of the PLC controlled load varies between $25 \mathrm{~W}$ to $3175 \mathrm{~W}$. The examined daily PLC controlled load pattern and the associated daily load duration curve are shown in Fig. 2 and Fig. 3, respectively.

\subsection{SYSTEM CONTROL}

The overall power system is fully controlled by a Programmable Logic Controller (PLC). Several signals regarding the solar irradiation, the hour of the day, the battery voltage, the load to be supplied and the various fuses condition constitute the inputs to the PLC. The PLC outputs are the various loads that are used at specific intervals for everyday time, composing the constant daily load curve. Taking this information into account the PLC is programmed to start and stop the operation of the DG when it becomes necessary, ie the DG mainly starts to operate when the load is relatively high and cannot be met by the battery-inverter subsystem. In addition, if the battery voltage is low during daytime the PLC is programmed not to operate the DG immediately, if the supplied load is not considerably high as it happens during cloudy intervals of the day. Finally, with the DG in operation the PLC cuts off the secondary charger of the battery bank when the total load exceeds the DG nominal power capacity.

\subsection{Meteorological Data}

The statistical solar data of the selected site for the years 2002-2006 were measured-recorded from he meteorological station with trade name BABUC-ABC by Lastem, installed at the mentioned site in the city of Xanthi, Greece since 2002 and at a height of $14 \mathrm{~m}$ (above ground level), for the considered PSs collects all necessary data for the assessment of the installed power unit. The 


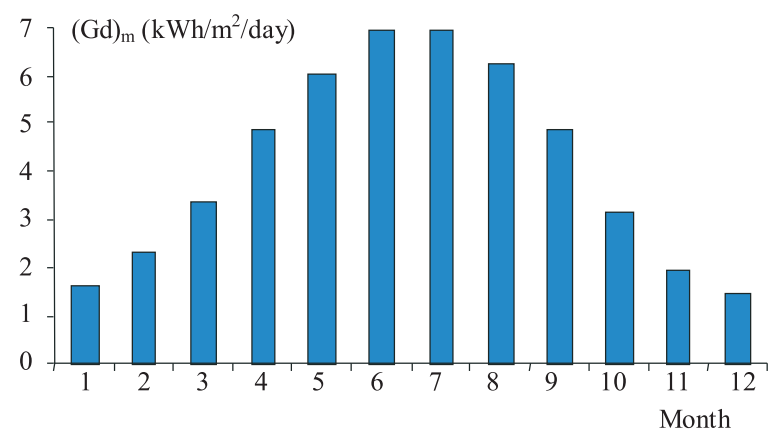

Fig. 4. Horizontal monthly daily mean irradiation $\left(G_{d}\right)_{m}$ for the examined site of Xanthi, Greece

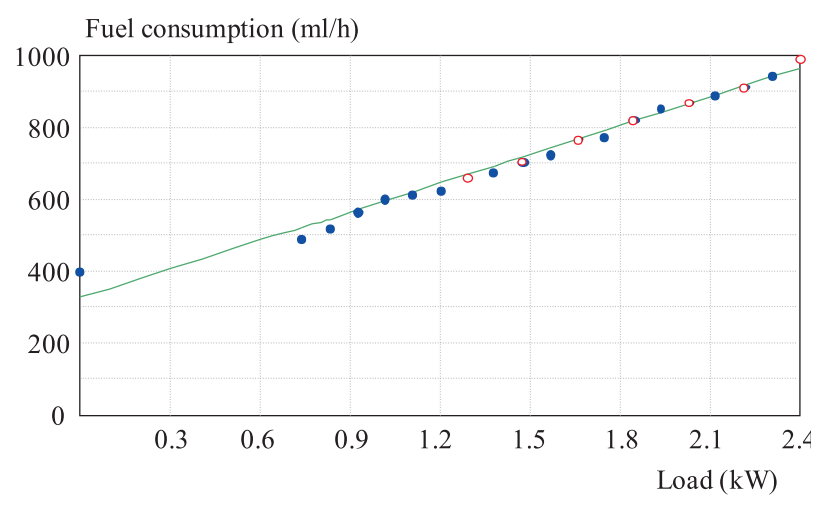

Fig. 5. FC as function of LS: - Least square method; - experimental values

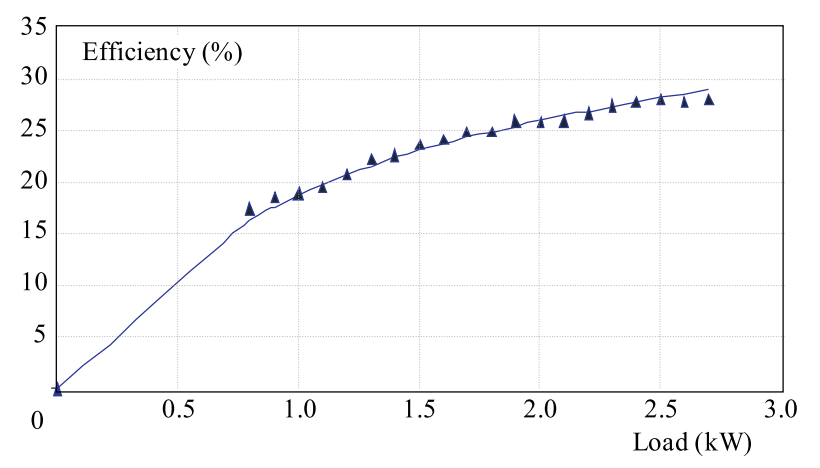

Fig. 6. Efficiency as function of LS: - Least square method; $\Delta$ experimental values

station provides global solar irradiation, ambient temperature, wind speed, wind angle, wind direction, humidity, atmospheric pressure, and rain gauge. The horizontal monthly daily mean irradiation $\left(G_{d}\right)_{m}$ for the assessed site is shown in Fig. 4.

\subsection{PS1 configuration}

In PS1 only a DG is used, see Fig. 1(a) and Table 1. For the purpose of serving the maximum load demand shown in Fig. 2 (ie $1850 \mathrm{~W}$ ) a YDG-3000SE with rated nominal output power of $2.5 \mathrm{~kW}$ is used. In order to determine the fuel consumption (FC) vs load supplied (LS) curve, extended experiments were conducted. Starting with load from $700 \mathrm{~W}$ to $2.5 \mathrm{~kW}$ by a step of $100 \mathrm{~W}$, five hour experiments were conducted and the consumed fuel was measured. The values of coefficients $a$ and $b$ were calculated from the conducted 19 experiments using the least-square method as described in $\S 2.3$. The calculated values of coefficients $a$ and $b$ for the examined DG were obtained by using (10) and (11) and are shown in Table 2. The calculated FC as function of LS is shown in Fig. 5.

Table 2. Numerical values of coefficients $a$ and $b$ for DG type Yanmar YDG-3000SE

\begin{tabular}{lcc}
\hline Coefficients & $a$ & $b$ \\
Numerical Values & 0.246 & 315.24 \\
Units & $\mathrm{ml} / \mathrm{Wh}$ & $\mathrm{ml} / \mathrm{h}$ \\
\hline
\end{tabular}

Using the information of Fig. 5 the daily fuel consumption was calculated to be 9.684 lt., whereas by using (13) the DG efficiency as function of LS is computed and shown in Fig. 6.

Similarly the average efficiency of PS1 is calculated to be $7.09 \%$ due to the many hours of operation supplying low load. It is to be noted that in this case at least two identical DGs are to be used, since for practical reasons one DG unit should not operate continuously for a period longer than five hours.

\subsection{PS2 configuration}

In PS2, see Fig. 1(b) and Table 1, the DG was combined and supported with a 1000 Ah12 V battery bank, a $1250 \mathrm{~W}$ bidirectional inverter and a $60 \mathrm{~A}-12 \mathrm{~V}$ secondary charger. The capacity of the bidirectional inverter was selected to supply the base load, and being able to supply continuously load up to $30 \%$ of the DGs nominal capacity when the latter starts its no load operation and the capacity should be at least $750 \mathrm{~W}$. The secondary charger's capacity was selected to secure economic use of the consumed fuel when the DG is in operation and increase its performance, while combined with the bidirectional inverter (operating also as charger) it would not charge the battery bank with current higher than the recommended by the manufacturer. The capacity of the battery bank is selected to be able to serve the daily base load and to be charged by both the bidirectional inverter and the secondary charger without severe fast charging that would decrease its life cycle. In this case one DG is enough to serve the peak load and charge the batteries, which combined with the inverter serve the base load. In such cases a second DG is only used as a backup in case of malfunction. The PLC was programmed not to put the DG in operation if the supplied load was less than $275 \mathrm{~W}$. Also, when the load supplied by the DG was more than $60 \%$ of its rated capacity the secondary charger was switched off and the battery was charged only by the bidirectional inverter which, when the DG is in operation, operates as charger. The conducted experiment lasted ten days. The DG daily operation was on the average 5 hours and 32 
minutes, with $3.843 \mathrm{lt}$. fuel consumption. The respective average efficiency of the DG was $24.36 \%$ and the total system efficiency was computed to be $17.86 \%$.

\subsection{PS3 configuration}

In PS3, see Fig. 1(c) and Table 1, a PV- DG HPS with battery storage was implemented to serve the prescribed load demand. The PS3 consists of the components used in PS2 with an additional PVG and its BOS. Based on the information of Fig. 3 loads above $750 \mathrm{~W}$ appear for $12.5 \%$ of the day and correspond to $30 \%$ of the DGs nominal capacity (minimum accepted part load level). Thus, in this case the load was divided into the "low" load (up to $750 \mathrm{~W}$ ) and the "high" load (above $750 \mathrm{~W}$ ). The "high" load was entirely supplied by the DG, whereas the "low" load was mainly supplied by the PV-batteryinverter subsystem. The latter subsystem was designed to supply the entire "low" load for the summer period, whereas in winter part of the load was supplied by the DG. The energy produced by the PVG was calculated using the associated meteorological data, and the capacity of the PVG was calculated by the methods described in [17]. The required energy demand in Wh consumed from the load being supplied by the PVG is:

$$
\begin{aligned}
E_{P V}= & E_{L}-E_{D G}-E_{B A T-D G}=E_{L}-E_{D G}-t_{1}\left(P_{c h 1}\right. \\
& \left.+P_{c h 2}\right) n_{c h 1,2} n_{b a t} n_{i n v}-t_{2} P_{c h 1} n_{c h 1} n_{b a t} n_{i n v}
\end{aligned}
$$

where: $E_{L}$ is the total energy required for the daily load pattern demand; $E_{D G}$ is the energy consumed by the load supplied directly from the DG, $E_{B A T-D G}$ is the energy consumed by the load from the battery which was stored while the DG was in operation, $t_{1}$ is the number of hours that both chargers are in operation, $P_{c h 1}$ is the rated power of charger1, $P_{c h 2}$ is the rated power of charger2, $n_{c h 1,2}$ is the total efficiency of the energy conversion from $\mathrm{AC}$ to DC by the chargers, $n_{b a t}$ is the battery efficiency, $t_{2}$ is the number of hours that only one of the chargers was in operation, and $n_{c h 1}$ is the efficiency of the energy conversion from AC to DC by the charger which was in operation. The computed results obtained from (14) showed that the needed battery capacity is $939 \mathrm{Ah}$, which means that 10 batteries of $100 \mathrm{Ah}$ each must be used. Based on (15) and by using the polycrystalline Eurosolare PL-810 solar module, the above methods showed that six solar modules of this type will compose the PVG. In this system the PLC was programmed differently to take into account the time of the day and the possibility of short cloudy intervals that might lead to battery voltage drop, resulting in DG operation. Also the DG would not operate if the load to be supplied by the system was less than $425 \mathrm{~W}$, resulting to an even more efficient use of the fuel and to increased performance of the DG. The actual duration of the conducted experiment lasted six months, the results of which when combined with the related meteorological data, may be used by extraction for one year period operation of the system. The mean daily fuel consumption was 3.213 lt for a 4 hour and 32 minutes of daily DG operation. The respective average efficiency of the DG was $24.66 \%$, the average efficiency of the PVG was $10.11 \%$ and the total system's efficiency was computed to be $12.77 \%$. The associated computed results of the three examined cases are summarized in Table 3.

Table 3. Computed efficiency of DG and PVG, and overall efficiency of the three examined PSs

\begin{tabular}{lccc}
\hline & \multicolumn{3}{c}{ Examined Power Systems } \\
& PS1 & PS2 & PS3 \\
\hline DG efficiency (\%) & 7.09 & 24.36 & 24.66 \\
PVG efficiency (\%) & -- & -- & 10.11 \\
$\begin{array}{l}\text { Overall power system } \\
\text { efficiency (\%) }\end{array}$ & 7.09 & 17.86 & 12.77 \\
\hline
\end{tabular}

\begin{tabular}{|c|c|c|}
\hline & Examined System & Value \\
\hline Initial cost $(€)$ & $\begin{array}{l}\text { PS1 } \\
\text { PS2 } \\
\text { PS3 } \\
\end{array}$ & $\begin{array}{l}5100 \\
6090 \\
8886 \\
\end{array}$ \\
\hline $\begin{array}{l}\text { O\&M Cost } \\
\text { without } \\
\text { fuel cost }(€ / y r)\end{array}$ & $\begin{array}{l}\text { PS1 } \\
\text { PS2 } \\
\text { PS3 } \\
\end{array}$ & $\begin{array}{c}3094.11 \\
698.38 \\
580.83 \\
\end{array}$ \\
\hline Fuel Cost $(€ /$ yr $)$ & $\begin{array}{l}\text { PS1 } \\
\text { PS2 } \\
\text { PS3 } \\
\end{array}$ & $\begin{array}{c}3456.9 \\
1371.84 \\
1146.94 \\
\end{array}$ \\
\hline $\mathrm{NPC}(€)$ & $\begin{array}{l}\text { PS1 } \\
\text { PS2 } \\
\text { PS3 } \\
\end{array}$ & $\begin{array}{l}91044.27 \\
36954.65 \\
33966.39 \\
\end{array}$ \\
\hline $\operatorname{NPV}(€)$ & $\begin{array}{l}\mathrm{PS} 2 \text { vs } \mathrm{PS} 1 \\
\mathrm{PS} 3 \text { vs } \mathrm{PS} 1 \\
\mathrm{PS} 3 \text { vs } \mathrm{PS} 2\end{array}$ & $\begin{array}{c}50551.04 \\
53343.80 \\
2792.76 \\
\end{array}$ \\
\hline $\operatorname{IRR}(\%)$ & $\begin{array}{l}\mathrm{PS} 2 \text { vs } \mathrm{PS} 1 \\
\mathrm{PS} 3 \text { vs } \mathrm{PS} 1 \\
\mathrm{PS} 3 \text { vs } \mathrm{PS} 2\end{array}$ & $\begin{array}{c}452 \\
132 \\
18 \\
\end{array}$ \\
\hline PBP (years) & 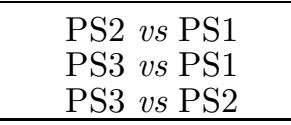 & $\begin{array}{l}0.19 \\
0.83 \\
7.92 \\
\end{array}$ \\
\hline $\mathrm{BCR}$ & 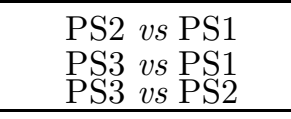 & $\begin{array}{l}52.06 \\
15.09 \\
2.00 \\
\end{array}$ \\
\hline $\mathrm{COE}(€ / \mathrm{kWh})$ & $\begin{array}{l}\text { PS1 } \\
\text { PS2 } \\
\text { PS3 }\end{array}$ & $\begin{array}{l}3.58 \\
1.45 \\
1.34 \\
\end{array}$ \\
\hline
\end{tabular}

Table 4. Economic data and computed results

\subsection{Economic analysis}

An economic analysis was performed taking into consideration the current Greek market prices for the used equipment: fuel cost $(0.978 € / \mathrm{lt})$, with a yearly increase in prices of $1.1 \%$, replacement of DG every $15000 \mathrm{hrs}$ of operation, replacement of battery bank every 3 years for PS2 and every 4 years for PS3, replacement of the bidirectional inverter and the secondary charger every 10 
years, taking into consideration the salvage value of the remaining equipment, and a discount rate of $7 \%$.

The relevant data for the economic assessment and the associated computed results are shown in Table 4 for a 20 year period of PS operation. It is to be noted that the indices NPV, IRR, PBP, BCR are computed assuming that the PS1 is the reference system (which is to be substituted either by PS2 or PS3). Based on the information of Table 4, it is seen that PS2 and PS3 are economically much more efficient systems than PS1, since despite their increased initial cost they have a PBP value less than one year. On the other hand, the PS3 compared to PS2 has increased initial cost but it is considered economically more efficient due to the considered long operational period of the system.

\section{CONCLUSIONS}

In this paper, three distinct PSs of equal rating that serve the same load demand are proposed and assessed techno-economically in a systematic manner. The obtained computational results showed clearly that the continuously declining prices in PVGs and their related BOS, combined with the increased fuel prices have made the use of such PS an economically efficient, and environmentally friendly solution for applications in remote areas.

The control of the operation of a PS by PLC contributes to the optimization of the DG utilization based on reduction of operating hours and, therefore, of associated fuel consumption and pollutants to the environment, resulting not only in more economical and efficient generation of electrical energy but also in extending the life time of the non-renewable energy sources. The PLC is programmed in different ways according to the special operating requirements of each PS being used.

From the conducted economic assessment analysis it is clear that the use of a PV-DG hybrid power system is the most attractive solution for such applications (in remote areas) since its period of operation is extended. The use of PS2 or PS3 results in substantial reduction of hours of DG operation if they are designed and programmed properly.

\section{Acknowledgement}

The authors are pleased to thank the Electrodome of Thessaloniki Construction Company for its cooperation on this research work.

\section{REFERENCES}

[1] RUTHER, R.-SCHMID, A. L.-BEYER, H. G.-MONTENEGRO, A. A.-OLIVEIRA, S. H. F.: Cutting on Diesel, Boosting PV: The Potential of Hybrid Diesel/PV Systems in Existing Mini-Grids in the Brazilian Amazon, 3rd World Conference on Photovoltaic Energy Conversion Osaka, Japan, May 11-18, 2003.

[2] VAlenciagA, F.-PUlEStON, P. F.: Supervisor Control for a Stand-Alone Hybrid Generation System Using Wind and
Photovoltaic Energy, IEEE Transactions on Energy Conversion 20 No. 2 (June 2005), 398-405.

[3] RUTHER, R.-MARTins, D. C.-BAZZO, E. : Hybrid Diesel/ Photovoltaic Systems Without Storage for Isolated Mini-Grids in Northern Brazil, Conference Record of the Twenty-Eighth IEEE Photovoltaic Specialists Conference, Anchorage, the USA, 2000, pp. 1567-1570.

[4] DEHBONEI, H.-NAYAR, C. V.-BORLE, L. : A Multi-Functional Power Processing Unit for Off-Grid PV Diesel Hybrid Power System, 35th Annual IEEE Power Electronics Specialists Conference, Aachen, Germany, 2004, pp. 1969-1975.

[5] NEHRIR, H. M.-LAMERES, B. J.-VENKATARAMANAN, G.-GEREZ, V.-ALVARADO, L. A. : An Approach to Evaluate the General Performance of Stand-Alone Wind/Photovoltaic Generating Systems, IEEE Transactions on Energy Conversion vol 15 No. 4 (Dec 2000), 433-439.

[6] GIRAUD, F.-SALAMEH, Z. M.: Steady-State Performance of a Grid-Connected Rooftop Hybrid-Wind Photovolotaic Power System with Battery Storage, IEEE Transactions on Energy Conversion 16 No. 1 (Mar 2001), 1-7.

[7] WAKAO, S.-NAKAO, K.: Reduction of Fuel Consumption in PV/Diesel Hybrid Power Generation System by Dynamic Programming Combined with Genetic Algorithm, Conference Record of the 2006 IEEE 4th World Conference on Photovoltaic Energy Conversion, Volume 2, Waikoloa, the USA, May 2006.

[8] WIES, R. W.-JOHNSON, R. A.-AGRAWAL, A. N.CHUBB, T. J.: Simulink Model for Economic Analysis and Environmental Impacts of a PV With Diesel-Battery System for Remote Villages, IEEE Transactions on Power Systems 20 No. 2 (May 2005), 692-700.

[9] KYOUNGSOO RO-RAHMAN, S.: Two-Loop Controller for Maximizing Performance of a Grid-Connected Photovoltaic-Fuel Cell Hybrid Power Plant, IEEE Transactions on Energy Conversion 13 No. 3 (Sep 1998), 276-281.

10] ABDin, E. S.-OSheiBA, A. M.-KHATER, M. M.: Modelling and Optimal Controllers Design for a Stand-Alone Photovoltaic-Diesel Generating Unit, IEEE Transactions on Energy Conversion 14 No. 3 (Sep 1999), 560-565.

11] Muselli, M.-NOTTON, G.-LOUCHE, A. : Design of Hybrid-Photovoltaic Power Generator, with Optimization of Energy Management, Solar Energy 65 No. 3 (1999), 143-157.

[12] MARKVART, T.-CASTANER, L.: Practical Handbook of Photovoltaics, Fundamentals and Applications, Elsevier, 2003.

[13] BOROWY, B. S.-SALAMEH, Z. M. : Optimum Photovoltaic Array Size for a Hybrid Wind/PV System, IEEE Transactions on Energy Conversion 9 No. 3 (Sep 1994), 482-488.

14] VAChtSevanos, G.-KAlaitzaKIS, K.: A Hybrid Photovoltaic Simulator for Utility Interactive Studies, IEEE Transactions on Energy Conversion EC-2 No. 2 (Sep 1987), 227-231.

[15] SINGER, S.-ROZENSHTEIN, B.-SURAZI, S. : Characterization of PV Array Output using a Small Number of Measured Parameters, Solar Energy 32 No. 5 (1984), 603-607.

[16] KARKI, R.-BILLINTON, R.: Reliability/Cost Implications of PV and Wind Energy Utilization in Small Isolated Power Systems, IEEE Transactions on Energy Conversion 16 No. 4 (Dec 2001), 368-373.

[17] Sandia National Laboratories, Stand-Alone Photovoltaic Systems - A Handbook of Recommended Design Practices, Photovoltaic Design Assistance Center, Albuquerque New Mexico, March 1995.

[18] Hellenic Republic, Ministry of Development, available at http://www.ypan.gr.

19] El-HEFNAWI, S. H.: Photovoltaic Diesel-Generator Hybrid Power System Sizing, Renewable Energy 13 No. 1 (1998), 33-40.

[20] SHAAHID, S. M.-ELHADIDY, M. A.: Economic Analysis of Hybrid Photovoltaic Diesel Power Systems for Residential Loads in Hot Regions - A Step to Clean Future, Renewable and Sustainable Energy Reviews 12 (2008), 488-503. 
[21] PAPAdOPOUlOS, D. P.-KAtsigiannis, P. A. : Biomass Energy Surveying and Techo-Economic Assessment of Suitable CHP System Installations, Biomass and Bioenergy 22 No. 2 (Feb 2002), 105-124.

[22] IRVING, G. : Modern Cost-Benefit Methods: an Introduction to Financial, Economic and Social Appraisal of Development Projects, The McMillan Press, Ltd., London/UK, 1978.

Received 18 September 2009

Demetrios P. Papadopoulos (1942) received the BSEE, $\mathrm{MS}$ and $\mathrm{PhD}$ degrees in Electrical Engineering from Marquette University, Milwaukee - Wisconsin, USA, in 1965, 1968 and 1970, respectively. During 1970-1972 he was Assistant Professor at the Department of Electrical Engineering of Gonzaga University, Spokane - Washington, USA. From 1972 to 1997 he was with the Public Power Corporation of Greece working on various special projects of power systems. From 1981 to August 2009 he was Professor and Director of the Electrical Machines Laboratory of the Department of Electrical and Computer Engineering at Democritos University of
Thrace (DUTh). From 1987-1988 he served as Vice-Rector at DUTh and from 1989-1991 as General Secretary of EasternMacedonia and Thrace Region of Greece. He is Life Senior Member of IEEE, Emeritus member of the Technical Chamber of Greece, and also of the Societies ПMЕ, TВП, HKN and $\Sigma \mathrm{X}$. His research interests are in: electrical machines and machine systems; power production using PVs, WECS, Smallhydro; and Cogeneration.

Eleftherios Z. Maltas (1981) received his engineering diploma and MS degrees from the from the Department of Electrical and Computer Engineering of Democritos University of Thrace, Greece in 2004 and 2007 respectively, where he is currently pursuing a $\mathrm{PhD}$ degree. He is Member of the Technical Chamber of Greece, Member of the Professional Chamber of Thessaloniki, Member of the Chamber for Small and Medium Sized Industries of Thessaloniki, also member of the Anatolia Alumni Society. His research interests are: in electrical machines; electrical applications of RES; and power electronics.

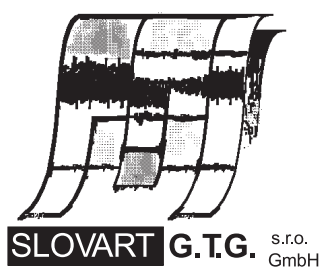

EXPORT - IMPORT
EXPORT - IMPORT

of periodicals and of non-periodically printed matters, books and CD-ROMs

Krupinská 4 PO BOX 152, 85299 Bratislava 5, Slovakia tel: ++421263839 472-3, fax: ++421263839485 info@slovart-gtg.sk; http://www.slovart-gtg.sk

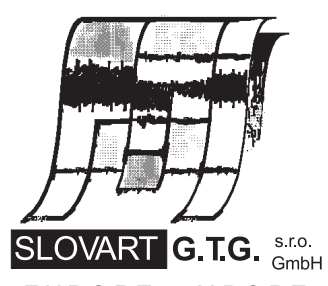

EXPORT - IMPORT 